ГREVIEW ARTICLE

Volume 16 Issue 22021

DOI: 10.21315/aos2021.16.2.1

ARTICLE INFO

Submitted: $31 / 08 / 2020$

Accepted: 17/06/2021

Online: $22 / 12 / 2021$

\section{The Shift of Dental Education During and Post COVID-19}

\author{
Ting Jing Kweha, , Ghee Seong Lima ${ }^{\mathrm{a}^{*}}$, Maria Angela Garcia Gonzalez ${ }^{\mathrm{a}}$, \\ Teng Kai Ong ${ }^{b}$

\begin{abstract}
${ }^{a}$ Department of Restorative Dentistry, Faculty of Dentistry, Universiti Malaya, 50603 Kuala Lumpur, Malaysia

${ }^{b}$ Department of Surgical Sciences, Division of Endodontics, Marquette University School of Dentistry, Milwaukee, Wisconsin 53233, USA

${ }^{c}$ Division of Restorative Dentistry, School of Dentistry, International Medical University, 57000 Kuala Lumpur, Malaysia
\end{abstract} \\ ${ }^{\star}$ Corresponding author: g.s.lim@um.edu.my
}

To cite this article: Kweh TJ, Lim GS, Gonzalez MAG, Ong TK (2021). The shift of dental education during and post COVID-19. Arch Orofac Sci, 16(2): 95-101. https://doi.org/10.21315/aos2021.16.2.1

To link to this article: https://doi.org/10.21315/aos2021.16.2.1

ABSTRACT

Education worldwide has been conducted in the traditional face-to-face classroom teaching style for ages, and this includes the education in dentistry. Since the introduction of online education and distance learning, teaching institutions have gradually made e-learning an integral part of teaching and learning activities. With the emergence of COVID-19 pandemic and closure of teaching institutions worldwide, the faculty of dentistry is amongst the many that were forced to leap onto the online education field abruptly. There is a sudden need for educators to resort to online teaching and e-learning becomes an essential tool to be developed as an alternative to traditional education methods. This article serves as a review to explore and discuss the common concerns and institutional readiness in delivering e-learning and review the methods currently utilised during this time of crisis.

Keywords: Computer-assisted; COVID-19; dental education; distance learning; e-learning

\section{INTRODUCTION}

Dentistry has been traditionally taught in the face-to-face classroom teaching style. This learning process usually involves lectures, tutorials, problem-based learning (PBL), counselling sessions and laboratory and clinical based practical teaching. Recently, with the advancement in digitalisation, the education system has tried to move towards paperless and contactless teaching through various online platforms. Hence, most teaching institutions have taken efforts to invest in online education and web-based training (e-learning) for the past two decades after the introduction of distance learning (Hinman, 1996) and the digitalisation era. The rapid growth of internet technology, telecommunication system and increased affordability of personal digital assistants (PDAs) facilitated the advances of digital technology (Salas et al., 2002). Dental schools in Malaysia are preparing to embrace this technology and are gradually making e-learning an integral part of teaching and learning activities. While some institutions have already used online resources for active teaching, other institutions are still using face-to-face teaching. The online platform for some institutions has been used mostly 
for announcements, student and lecturer forum, as a repository of teaching materials that students and lecturers may review, or a vehicle to conduct evaluation but performed within faculty premises. The dental preclinical and clinical e-learning did not receive much attention until the pandemic disrupted dental education globally. With the emergence of COVID-19 pandemic which caused worldwide educational institutions closure, the faculty of dentistry is amongst those who were forced to find alternatives and most likely substitute traditional teaching in online education. It is of utmost importance that educational institutions continue the teaching and learning process of students. Hence, this article serves as an exploration to discuss the common concerns and institutional readiness in delivering e-learning and review the methods currently utilised during this time of crisis.

\section{Basic Requirements for a Successful e-Learning}

Based on the literature search and authors' experiences, teaching and learning activities should be guided by the course learning outcomes and focus on effective educational assessment simultaneously. The weightage of each component to be taught should be assigned based on the learning objective. Similarly, while drafting an electronic educational content for dental programmes, this blueprint should be followed while delivering knowledge. E-learning has several advantages over traditional classroom learning, namely being learner-centred, providing flexibility in terms of time and location, having the option to make it available for public or even global audience and capability of knowledge reuse (Zhang et al., 2004). Bearing these in mind, educators should make use of these advantages for an effective e-learning programme. Meanwhile, the downside of it such as lack of immediate interpersonal interaction, increased preparation time and potential for frustration and confusion have been reported (Zhang et al., 2004). Students' perception towards the transformation of dental education into online format were vastly different, but generally limitations were described as lack of hands-on which cannot be offered by virtual case presentations, constant staring at computer screen causing fatigue and difficulty to adapt the teaching methods (Van Doren et al., 2020). Generally, a welldesigned online learning activity should be learner centric, providing logical and relevant content, interactive, flexible and able to provide for user assessment (Childs et al., 2005). Besides that, it should be supported by appropriate and sufficient hardware such as computers, internet services and online platforms and applications.

\section{Barriers Faced while Implementing e-Learning}

The anticipated drawback of online education is its reliance on internet connectivity (Laprairie \& Hinson, 2006), whereby in Malaysia, the internet access and its variation of internet connectivity depends on the geographic locations such as rural and urban area; and whose accessibility and affordability may be dictated by socioeconomic status. A 2017 Q1 report showed that Malaysia had broadband penetration rate of $81.8 \%$ (per 100 households), and the figures differ among states which ranges from $56.0 \%$ to $200.2 \%$ (per 100 inhabitants) (Malaysian Communications and Multimedia Commission, 2017). Moreover, students will have to own some sort of PDAs in order to access online education learning systems. A survey done in 2015 targeting students from three universities in Malaysia showed that up to $81.2 \%$ owned smartphones and laptops, and $92 \%$ of the respondents used mobile devices for distance learning (Al-Arabiat et al., 2015). We could expect an increase in device ownership and accessibility to hi-speed internet, but there would be a disadvantaged minority group who may not afford and have access to the technology. Therefore, the challenge would be to overcome connectivity issues and electronic device ownership, especially among poverty-stricken families. A national approach to tackle this problem is an 
educational institution initiative to provide loans to eligible students to purchase portable broadband and electronic devices.

Organisational barriers are of concern too, considering the financial investment for the hardware and software required, training for educators, and technical support especially of information technology (IT) services. The current pandemic situation sees the sudden need of educators to conduct online teaching. This has notably affected both educators and learners, as there is a lack of buffering time for both parties to adapt to this new norm. Management must provide continuing education for lecturers and staff who do not have the skill to use online platforms. Online platforms that allow access to a number of participants for a certain period of time should be provided in a userfriendly manner. The technical staff should explore ways to accommodate the number of students during online learning and teaching. Teaching staff through training sessions on these new technologies is a must and should include teaching guidelines. Furthermore, there should be support for staff who finds difficulty in adapting to these technologies and platforms. The use of educational principles in transitioning to online teaching should be taken in consideration. The access of students to the library should be unlimited. This access, however, will be an additional expense to the institution. From a managerial viewpoint, cost effectiveness is vital while ensuring education takes place. It is essential to have a policy on basic computer literacy in the near future for a transition towards online education.

One of the major concerns for dental education is the laboratory, pre-clinical and clinical sessions which is a major part of dental curriculum. Most dental schools worldwide had to suspend laboratory, preclinical and clinical facilities because the physical arrangement does not allow the recommended physical distancing between students, instructors and/or patients on the aforementioned facilities. The nature of providing clinical service to patients involves close contact at a distance of between 14 to 16 inches between the clinician and the patient. The aerosol that may be generated by the dental procedure is a source of concern among dental professionals. Dental skills training involves gathering and close interaction of individuals in an enclosed space, putting the patients, students and the clinical supervisors at risk of infection. The physical challenges of providing physical distancing will involve a bigger space as well as provisions for aerosol scavenging units and air filtration and exchange units. The provision of Level 3 personal protective equipment (PPE) may be the norm in the new normal of dental practice. Currently, there is no method developed to conduct practical training online since its objective is for hand dexterity/clinical skills practice. There are suggestions to explore the possibility of using robot simulation and clinical virtual simulation systems, which could be useful in incorporating tactile sensation. Also, the students could be provided with dental simulator phantom head models and associated accessories in order to allow them to perform pre-clinical projects at the comfort of home. However, this approach will be very costly and eventually it might not provide the similar tactile sensation while dealing with real human teeth, not to mention the absence of direct in-house expertise supervision (Sharka et al., 2020). Therefore, the cost-effectiveness and cost-benefit of the virtual simulation platforms should be assessed prior to partial or full implementation of these platforms in dental schools.

\section{Platforms for e-Learning}

E-learning can be delivered synchronously or asynchronously (Ruiz et al., 2006), where the former refers to education content being delivered real-time and students receive information simultaneously as teaching takes place; whereas asynchronous delivery allows student to pace their own learning with interaction taking place after with feedback technologies. The current COVID-19 pandemic leads to a mushrooming of 
educational dental webinars using various platforms and applications including public access and university-based platforms. In fact, this approach has been commonly utilised before the pandemic crisis and recently many dental schools have used this method to conduct synchronous online lectures. There are multiple services available and no consensus has been reached among universities and organisations on the most suitable software to use in distance learning. The new platform may spark interest and attention initially. The distractions present in the home may prove to be too attractive to sustain focus on online teaching. The features of various methods commonly utilised in conducting synchronous e-learning is presented in Table 1.

\section{Assessment Considerations}

Another important component in education is the assessment system. There are concerns that the current graduating batch of students may lack clinical experience due to the suspension of practical training (Gaur et al.,
2020). This batch of students faced the direct impact of COVID-19 in terms of their academic programme as the immediate shift to online learning cannot completely replace the live in-person sessions, especially the experiences gain from real time patient management and interaction. It is particularly important to assess effectiveness of education delivery methods and the learning of students as well as student acceptance of methods to be used. During the pandemic, there should be a revision towards the assessment system if dental education can be delivered online. The dental educational board should consider changes especially towards the professional exam and licensure examination formats for dental students and graduates, respectively. One debatable suggestion to explore the policy of using a pass/no-pass assessment method instead of the widely used cumulative grade point average (CGPA) grading. The disruption of the academic timetable restricted students to a limited number of classes and exams got replaced with alternative assignments. Adoption of

Table 1. Synchronous learning platforms

\begin{tabular}{ll}
\hline Social media & Most commonly used apps for public webinar. \\
Facebook Live & Accessibility for global audience without limit. \\
Instagram Live & Minimal data consumption. \\
YouTube Live & Lacking real-time interaction, any form of activity mainly through comments \\
& section. \\
& A lot of unnecessary emoticons and distraction. \\
& Unable to control the access of participants. \\
& Playback available. \\
& Live session for Instagram limited to one hour per session. \\
& Suitable for smaller group participants. \\
Telecommunication platform & Allow better interaction between trainers and students. \\
Skype & Allow sharing of documents, presentations slides and other visual documents. \\
Microsoft Teams & Participation is by invitation only. \\
Google Meet & Audio-visual quality inferior compared to webinar software (depending on the \\
& speed of internet). \\
& Heavier data consumption. \\
& Better audio-visual quality. \\
Webinar software & Subscription needed for better features, otherwise limited time and audience \\
Zoom & pax for free version. \\
GoToMeeting & Recording feature available. \\
& Participation is by invitation only. \\
Able to live stream to Facebook for public audience. \\
Heavier data consumption. \\
If the meeting is across continents, there is a limit of time as well. \\
\end{tabular}


the pass/fail policy might give students some breathing room, with evidence showing that this method displayed superiority in terms of students' well-being (Wasson et al., 2016).

Evaluating written examinations has raised many hindrances. These include the ability to properly invigilate the students online including the number of students one can properly invigilate, the need for students to have an additional device for the invigilator to observe them, as well as prevention of cheating during the examination. The use of multiple-choice questions (MCQs) or one best answer (OBA) makes it convenient but then it may limit the evaluation to rate knowledge per se and may not measure the reasoning and critical thinking of a student. Essay questions may be more suitable for this purpose. The use of problem-based learning (PBL), case-based learning (CBL) and clinical-based reasoning (CBR) can be adopted in an online format. These aid in the development of critical thinking and reasoning part of the dental curriculum and can be modified to suit on-line teaching. In other words, the passing of the dental undergraduate is based on their competency level or their ability to practice safely and independently as a beginning dental practitioner. There should also be measures to monitor online assessment systems or distance examination to avoid possible fraudulence and schools must employ stringent guidelines to reduce this risk.

\section{Dental Education Compared to Non-Dental Education}

Unlike the non-dental field, one of the major concerns for dental education is the laboratory, pre-clinical and clinical sessions serve as a major part of dental curriculum. Owing to the involvement in both clinical and soft skills, the lack of hands-on and physical interaction with human beings may impede the complete experience in dental education. Teaching of courses that require practical training can be trying during the pandemic. Both medical and non-medical courses alike need to modify to accommodate the challenges faced and adapt to the changes. Several non-medical courses such as mechanical engineering are of handson and project-based learning too. While conducting the classes remotely, engineering online practical classes may be performed with the required materials and tools needed mailed or shipped to students; and ingenuity to find substitutes for expensive equipment was triggered. It can prove to be a motivating factor that triggers critical thinking and analysis (Gallagher, 2020). Medical and para-medical courses, on the other hand, would need practical training in the clinics that would require interaction with patients. Medicine, dentistry and nursing programmes would need face to face practical training to develop generic skills such as communication skills and teamwork skills that require interaction with different patients and members of the health team (Dewart et al., 2020; Hilburg et al, 2020; Salgado \& CastroVale, 2020). While practical work in preclinical sessions prepares the students to acquire the basic skills to perform simple procedures on a patient, the theoretical background is as important in further harnessing this skill. Nevertheless, generic skills may not be well developed without the in-person interaction with the patients. True life situations are vital to provide the environment to train students in this aspect. Aside from the technical skills, generic skills are developed in clinical sessions. There will not be any substitute for clinical training. Face-to-face clinical teaching needs to be used with the deployment of the vaccine with caution as new variants of the virus are evolving.

\section{Future Directions}

While COVID-19 has caused challenges physically and mentally, it has also created opportunities: Massive open online classes, social media live interactions, recorded lectures and virtual conferences (Camargo et al., 2020; Gaur et al., 2020). The dental fraternities including academic institutions, private sectors, dental industry as well as dental associations and organisations are 
in need to empower themselves to surf the digital wave. Moreover, before the COVID-19 era, there was a survey done suggesting that asynchronous format could be an effective way to deliver postgraduate dental course (Kunin et al., 2014). The utmost advantage of face-toface and synchronous learning compared to asynchronous models is the privilege to enjoy student-instructor and student-student interaction. Hence, the authors suggest putting more emphasis on this aspect to improve social changes while delivering synchronous lectures online. Meanwhile, in regard to asynchronous e-learning, it may be helpful to project a clear audio presentation and visual explanation with accurate transcription (Kunin et al., 2014). The challenge is to keep students' attention to the lecture. Use of more interactive methods may prove to be challenging to both students and lecturers. While students lose the advantages of face-to-face interactions, the ongoing pandemic situation allows them to learn new skills and their adaptive capabilities are enhanced.

Dentistry is one of the high-risk profession prone towards cross-infection, which is a worrying situation when the recently deployed vaccine raised concerns regarding its proven protection against the COVID-19 infection. However, the American Dental Association (ADA) reported that less than $1 \%$ of the practising dentist in the United States were estimated to be COVID-19 positive (Versaci, 2020). Allowing dental clinics to operate under the "new norm" with strict standard operating procedures (SOPs) and infection control strategies is the way forward. Dental services are one of the essential services and dental education relies heavily on this part to produce competent dentists. Undeniably, the integration of e-learning into the existing dental education curriculum is the present directions needs to work towards proven by multiple reports showing the effectiveness and acceptance of e-learning (Zhang et al., 2004; Childs et al., 2005; Laprairie \& Hinson, 2006).

\section{CONCLUSION}

Dental education could be revamped by introducing blended learning while allowing students to return safely to campus for clinical training. Online education will serve as a catalyst of paradigm shift seeing dental educators taking the role of facilitator. Considerations should be made to maintain sustainability of the programme as well as improvement in the engagement between educators and learners. There will definitely be a change or with a new norm in teaching and learning, where educators will require more preparation time and face more difficulties in teaching online; while students need to be mature, responsible and self-disciplined in order to benefit from the programme. Nonetheless, e-learning will be the alternative in a worst-case scenario to substitute for the traditional educational method. E-learning is the essential tool to be developed and adopted in the present dental education situation.

\section{REFERENCES}

Al-Arabiat D, Wan Ahmad WF, Sarlan A (2015). The barriers to adoption of mobile learning by HEIs in Malaysia: An exploratory study. f Adv Res Design, 14(1): 1-9.

Camargo CP, Tempski PZ, Busnardo FF, Martins MA, Gemperli R (2020). Online learning and COVID-19: A meta-synthesis analysis. Clinics (Sao Paulo), 75: e2286. https://doi.org/10.6061/clinics/2020/e2286

Childs S, Blenkinsopp E, Hall A, Walton G (2005). Effective e-learning for health professionals and students-barriers and their solutions. A systematic review of the literature-findings from the HeXL project. Health Info Libr F, 22(Suppl 2): 20-32. https://doi.org/10.1111/j.14703327.2005.00614.x 
Dewart G, Corcoran L, Thirsk L, Petrovic K (2020). Nursing education in a pandemic: Academic challenges in response to COVID-19. Nurse Educ Today, 92: 104471. https://doi.org/10.1016/j.nedt.2020.104471

Gallagher MB (2020). Teaching mechanical engineering in a pandemic. MIT News. Retrieved 20 November 2020 from https:// news.mit.edu/2020/teaching-mechanicalengineering-in-a-pandemic-0918

Gaur U, Majumder MAA, Sa B, Sarkar S, Williams A, Singh K (2020). Challenges and opportunities of preclinical medical education: COVID-19 crisis and beyond. SN Compr Clin Med, 20(2): 1992-1997. https://doi.org/10.1007/s42399-020-00528-1

Hilburg R, Patel N, Ambruso S, Biewald MA, Farouk SS (2020). Medical education during the coronavirus disease-2019 pandemic: Learning from a distance. Adv Chronic Kidney Dis, 27(5): 412-417. https://doi.org/10.1053/j.ackd.2020.05.017

Hinman AR (1996). Distance learning and distance education: A personal perspective. Am $\mathcal{F}$ Prev Med, 12(1): 5-8.

Kunin M, Julliard KN, Rodriguez TE (2014). Comparing face-to-face, synchronous, and asynchronous learning: Postgraduate dental resident preferences. F Dent Educ, 78(6): 856-866. https://doi.org/10.1002/j.0022 $-0337.2014 .78 .6 . t b 05739 . x$

Laprairie KN, Hinson JM (2006). When disaster strikes, move your school online. $\mathcal{F} E d u c$ Technol Syst, 35(2): 209-214. https://doi. org/10.2190/d154-xk20-7264-5013

Malaysian Communications and Multimedia Commission (2017). $1 Q \quad 2017$. Communications \& Multimedia: Facts \& figures. Retrieved 15 April 2020 from https://www.mcmc.gov.my/skmmgovmy/ media/General/pdf/1Q17-facts-figures.pdf

Ruiz JG, Mintzer MJ, Leipzig RM (2006). The impact of e-learning in medical education. Acad Med, 81(3): 207-212. https://doi.org/ 10.1097/00001888-200603000-00002
Salas E, Kosarzycki MP, Burke CS, Fiore SM, Stone DL (2002). Emerging themes in distance learning research and practice: Some food for thought. Int $\mathcal{f}$ Manag Rev, 4(2): 135-153. https://doi.org/10.1111/ $1468-2370.00081$

Salgado H, Castro-Vale I (2020). Clinical communication skills training in dental medical education: The COVID-19 pandemic challenge. Healthcare (Basel), 8(4): $\quad 429$. https://doi.org/10.3390/ healthcare 8040429

Sharka R, Abed H, Dziedzic A (2020). Can undergraduate dental education be online and virtual during the COVID-19 era? Clinical training as a crucial element of practical competencies. MedEdPublish, 9(1): 215. https://doi.org/10.15694/mep .2020 .000215 .1

Van Doren EJ, Lee JE, Breitman LS, Chutinan S, Ohyama H (2020). Students' perceptions on dental education in the wake of the COVID-19 pandemic. F Dent Educ, 85(S1): 1187-1189. https://doi.org/10.1002/jdd .12300

Versaci MB (2020). ADA study finds COVID-19 rate among dentists less than $1 \% . A D A$ News. Retrieved 20 November 2020 from https://www.ada.org/en/publications/adanews/2020-archive/october/ada-study-findscovid-19-rate-among-dentists-less-than-1percent

Wasson LT, Cusmano A, Meli L, Louh I, Falzon L, Hampsey M et al. (2016). Association between learning environment interventions and medical student wellbeing: A systematic review. $\mathcal{F} A M A$, 316(21): 2237-2252. https://doi.org/10 $.1001 /$ jama.2016.17573

Zhang D, Zhao JL, Zhou L, Nunamaker JF (2004). Can e-learning replace classroom learning? Commun ACM, 47(5): 75-79. https://doi.org/10.1145/986213.986216 